\title{
Editorial
}

\section{Hydraulics and Hydrology in Mountain Areas}

\author{
Massimo GRECO \\ Department of Civil, Environmental and Architectural Engineering, University Federico II of Naples, Via Claudio 2180125 \\ Napoli, Italy \\ E-mail:grecom@unina.it
}

Citation: Massimo G (2014) Hydraulics and hydrology in mountain areas. Journal of Mountain Science 11(6). DOI: $10.1007 / \mathrm{s} 11629-014-2983-7$

(C) Science Press and Institute of Mountain Hazards and Environment, CAS and Springer-Verlag Berlin Heidelberg 2014

The 35th IAHR World Congress was held in Chengdu, China from September 8 to September 13 2013. The title of the conference was: "The Wise Finds Pleasure in Water: Meandering through Water Science and Engineering". During the congress, 1239 papers were presented in 139 sessions for oral presentations and 7 sessions for poster presentations.

After the Congress, a Committee was appointed to select some of the best papers presented at the Congress for publication, after a further enhancement, in a Special Issue of this Journal. The Committee, composed by Cheng Xiaotao, Li Yong and Massimo Greco selected more than 40 papers for their quality and whose content could have been interesting to readers of the Journal of Mountain Sciences, to be invited. The selected papers have been subjected to a regular peer review, with Massimo Greco acting as the Guest Editor. Three international reviewers of different countries were chosen for each paper, whom I wish to thank for their efforts. Some of the papers selected were not considered good enough during the review process, and were finally discarded. The eleven remaining are presented in this issue of the Journal. These papers offer a wide range of topics where Hydraulics and Hydrology

Received: 8 November 2014

Accepted: 12 November 2014 may be very relevant to the understanding and protection of mountain landscapes and ecosystems and to the reduction of hazards for the downstream areas.

Two papers, by Dermisis and Papanicolau, and by Tsakiris et al., consider the effects of large boulders, typically found in mountain streams, on the flow properties, with special attention paid to turbulence structure modification by the latter paper and on the bed alterations due to the presence of finer sediment by the former. Both effects may have a strong impact on the suitability of the aquatic habitat to fish species and may alter the downstream sediment transport.

One paper, by Pilotti et al., deals with the modeling of dam break in the special case of high mountain valleys. Emphasis is given to the selection of appropriate tools to fully take advantage of the Digital Elevation Model (DEM) of the terrain, and to automate the production of cross sections of the river by the DEM data. Moreover, the need of recurring, or not, to a twodimensional, depth averaged, model instead of a simpler mono-dimensional one is discussed and emphasized.

Other two papers investigate sediment transport by flow. The first, by Li et al., investigates on the basic principles of sediment transport in non-capacity conditions, i.e. when the effective 
transport rate is different from what could be calculated according to well known formulas referring to uniform flow conditions. The other one, by Wei et al., applies a sophisticated twodimensional coupled model for flow and sediment transport to model a very huge dam break flood occurred during the Late Quaternary in the Altai Mountains in Southern Siberia. In these extreme conditions the model results quantitatively agree with the geological evidence.

Four of the papers are instead devoting attention to debris and mud flows, which occur mostly on the steep mountainous slopes. The first, by Liang and He, introduces an alternate model for the frictional resisting forces in dry granular flows and compares its predictions against different constitutive models using a Lagrangian meshless technique (SPH). Another one, by Di Cristo et al., evaluates in the more common Eulerian framework the applicability of different simplified models to predict shallow mudflows using a general formulation for friction as a power law. The third one, by Stancanelli et al., offers a systematic experimental study on the mutual interaction of two debris flow deposits from tributaries into a main stream. The last of this group, by Chen et al., presents some remarks on the maintenance and design of debris flow drainage channels, one of the most used countermeasure against expected debris flow damages.

Another paper, by Wang et al., present experimental results on channel evolution after the removal of a dam, which is becoming a common scenario in many countries for protecting riverine environment. The Authors focus on the fate of the sediments that were stored in the dammed lake, and they compare scaled laboratory experiments with a simplified analytical model and field observations.

The last of the papers included in this issue, by Kuang et al., may appear a bit off topic, since it analyzes the runoff at the Yangtze estuary. However, since the employed method has been devised for the analysis of the time series and for the identification of the main cyclic components, it is general and may be applied to analyze the changes induced by different land uses and policies in other basins.

The many contributions presented in this volume, then, show how Hydraulics and Hydrology may help in understanding the evolution of mountain landscapes and ecosystems, protecting them without impacting against the development of the lowlands downstream, nor increasing their risk by flood and debris flow hazards.

\section{Acknowledgements}

Besides the big "thank you" to all the reviewers for their precious contribution in reviewing the papers, I wish to thank the editorial staff of the Journal, mainly QIU Dunlian and XIANG Li (Lily) for the support and help with all the problems that we had to face. And of course the IAHR Congress Local Organizing Committee, headed by WANG Zhaoyin for setting up this opportunity of presenting some best papers of the Congress to a wider audience through this special issue of JMS, and for bestowing me with the honor of being the guest editor of this issue, which I think I have paid for by the hard work in preparing it. 